Jurnal ABDINUS : Jurnal Pengabdian Nusantara, 2 (2), 2019, 108-114

Available online at: http://ojs.unpkediri.ac.id/index.php/PPM

DOI: https://doi.org/10.29407/ja.v2i2.12471

\title{
Diversifikasi Produk Pangan Olahan Berbasis Buah Pepaya Dalam Meningkatkan Kesejahteraan Masyarakat Kelurahan Karang Joang Balikpapan Kalimantan Timur
}

\author{
Nur Amaliah', Ria Setyawati', Farida ${ }^{1}$, Ida Suriana ${ }^{1}$, Abdul Gafur ${ }^{1}$ \\ ${ }^{1}$ nur.amaliah@poltekba.ac.id \\ ${ }^{1}$ Jurusan Perhotelan, Program Studi Tata Boga \\ ${ }^{1}$ Politeknik Negeri Balikpapan
}

Received: 1809 2018. Revised: 2609 2018. Accepted: 09012019

\begin{abstract}
One of the Rukun Tetangga which is the center of papaya in Balikpapan City is RT 19 Kelurahan Karang Joang Balikpapan Utara. The potentials of papaya fruit reaches 10 tons per month or around 140 tons in year. Papaya agricultural land continues to grow 10 to 20 percent. The problem is that farmers only sell their papaya in a fresh condition, even many are damaged due to too much harvest and not sold in the market. The community does not know about the use of papaya in product development so that the method used to solve the problems of the Karang Joang community, especially RT 19 , is to socialize and provide materials related to food diversification. The results obtained from this community service are giving material and understanding to the women of Cempaka 19 farming women regarding the processing of papaya and training in making products including making abon and semprong papaya, and providing assistance in processing equipment to support the production of women mothers Cempaka 19 farm.
\end{abstract}

Keywords: Processed Food, Papaya, Welfare

\begin{abstract}
Abstrak: Salah satu Rukun Tetangga yang menjadi sentra pepaya yang ada di Kota Balikpapan adalah RT 19 Kelurahan Karang Joang Balikpapan Utara. Potensi buah pepaya mencapai 10 ton per bulan atau sekitar 140 ton per tahun. Lahan hasil pertanian pepaya terus bertambah 10 hingga 20 persen. Permasalahannya petani hanya menjual pepaya mereka dalam keadaan segar, bahkan banyak yang rusak dikarenakan panen yang terlalu banyak dan tak laku dipasaran. Masyarakat belum mengetahui pemanfaatan pepaya dalam pengembangan produk sehingga metode yang dilakukan untuk menyelesaikan permasalahan masyarakat Karang Joang khususnya RT 19 yaitu melakukan sosialisasi dan pemberian materi terkait diversifikasi pangan. Hasil yang diperoleh dari pengabdian kepada masyarakat ini yaitu memberikan materi dan pemahaman kepada ibu-ibu wanita tani Cempaka 19 terkait pengolahan dari pepaya serta melakukan pelatihan pembuatan produk meliputi pembuatan abon dan pembuatan semprong pepaya, dan memberikan bantuan alat pengolahan untuk mendukung produksi ibu-ibu wanita tani Cempaka 19.
\end{abstract}

Kata kunci: Pangan Olahan, Pepaya, Kesejahteraan 


\section{Jurnal ABDINUS : Jurnal Pengabdian Nusantara, 2 (2), 2019, 108-114}

Nur Amaliah, Ria Setyawati, Farida, Ida Suriana, Abdul Gafur

\section{ANALISIS SITUASI}

Kelurahan Karang Joang, Balikpapan Utara akan difokuskan pada pengembangan kawasan pertanian. Masyarakat Karang Joang umumnya berpenghasilan dari usaha pertanian. Terdapat tidak kurang 40 kelompok tani dengan jumlah anggota mencapai 1.500 orang. Umumnya, mereka hanya menjual produk hasil pertanian mereka tanpa nilai tambah. Sehingga tidak banyak keuntungan yang bisa diperoleh masyarakat. Kawasan ini memiliki banyak potensi lokal, diantaranya adalah hasil buah pepaya mini dan pepaya California yang dapat diolah menjadi produk pangan yang memiliki nilai ekonomi tinggi. Komoditi lainnya adalah tanaman ubi kayu (singkong) yang dapat diolah menjadi tepung mocaf sebagai pengganti tepung terigu, sekaligus menekan ketergantungan terhadap produk luar daerah maupun impor. Selain singkong dan buah pepaya, Karang Joang juga menyimpan potensi lain yakni buah naga yang dapat diolah menjadi snack, keripik, maupun permen dan buah salak yang dapat diolah menjadi manisan dan sirup.

Kesemua potensi tersebut belum dikelolah secara maksimal oleh masyarakat setempat terkhusus buah pepaya mini dan Pepaya California. Oleh karenanya diperlukan upaya dari berbagai pihak dalam mendisign kreatifitas dan inovasi masyarakat setempat sehingga dapat memberi nilai tambah dan meningkatkan kesejahteraan petani dan masyarakat. Dari hasil observasi dan wawancara terhadap pepaya mini dan Pepaya California yang diawakili ibu RT 19 yang juga menjabat sebagi ketua Kelompok Tani Cempaka 19 yaitu Ibu Armita dan salah satu kelompok tani budidaya pepaya mini dan Pepaya California yaitu Bapak Faharuddin, diperoleh data bahwa selama ini, petani secara langsung menjual hasil pertanian mereka ke pengepul dengan harga sangat rendah. Harga rata-rata buah pepaya mini hanya Rp7.000 per buah, sementara harga pasaran Rp mencapai 15.000 per kg.

\section{PERMASALAHAN MITRA}

Berdasarkan pembahasan dan hasil observasi, maka permasalahan mitra dapat diidentifikasi bagaimana managemen yang tepat dalam organisasi kelompok tani, bagaimana mengolah buah pepaya mini menjadi produk pangan yang dapat menambah nilai ekonomi masyarakat RT 19 Karang Joang yang didasarkan pada permintaan pasar, bagaimana mengadakan persyaratan perijinan berupa P.IRT dan DEPKES dari produk yang telah dihasilkan. 


\section{Jurnal ABDINUS : Jurnal Pengabdian Nusantara, 2 (2), 2019, 108-114}

Nur Amaliah, Ria Setyawati, Farida, Ida Suriana, Abdul Gafur

\section{SOLUSI DAN TARGET}

\section{A. Solusi Yang Ditawarkan}

Berdasarkan uraian permasalahan mitra di atas dapat ditentukan solusi dan sekaligus metode kegiatan yaitu "Diversifikasi Produk Pangan Olahan Pepaya Dalam Meningkatkan Kesejahteraan Petani Karang Joang Balikpapan" dalam menjawab permasalahan yang sedang dihadapi oleh mitra, yaitu diantaranya membuat pengelolaan organisai kelompok tani yang ada di RT 19 Karang joang yaitu Kelompok Wanita Tani Cempaka 19, melaksanakan pelatihan pengolahan produk olahan pepaya mini dan pepaya California yaitu semprong (egg roll) pepaya dan abon pepaya, membantu mengadakan persyaratan perijinan berupa P.IRT dan DEPKES dari produk semprong dan abon pepaya.

B. Target Luaran

Secara pelaksanaan target luaran pelaksanaan kegiatan Pengabdian Kepada Masyarakat adalah produk hasil warga binaan didaftarkan di Dinas Kesehatan kota Balikpapan untuk memperoleh izin P.IRT. Selain itu, akan dibina secara berkesinambungan hingga terbentuk sebagai desa produktif/binaan yang mampu secara mandiri memanfaatkan seluruh potensi perekonomian yang dimiliki, meliputi SDM, SDA, dan letak geografis RT 19, dengan tujuan untuk menciptakan kesempatan kerja bagi masyarakat setempat sehingga berdampak positif terhadap peningkatan pendapatan masyarakat. Ada pun jumlah peserta pelatihan di RT mitra sebanyak 20 orang.

Capaian luaran yang akan dihasilkan dalam program pengabdian kepada masyarakat ini dapat dilihat pada tabel 1 di bawah ini:

Tabel 1. Rencana Target Capaian Tahunan

\begin{tabular}{|c|c|c|c|}
\hline No & Jenis Luaran & & Indikator Luaran \\
\hline \multirow[t]{5}{*}{1} & \multirow{3}{*}{$\begin{array}{l}\text { Publikasi Ilmiah di } \\
\text { Jurnal 1) }\end{array}$} & Nasional & Tidak ada \\
\hline & & Internal Poltekba & Tidak ada \\
\hline & & $\begin{array}{l}\text { Eksternal Tidak } \\
\text { Terakreditasi }\end{array}$ & published \\
\hline & \multirow[t]{2}{*}{ Internasional } & Tidak Terindeks & Tidak ada \\
\hline & & Terindeks & Tidak ada \\
\hline \multirow[t]{3}{*}{2} & \multirow[t]{3}{*}{ Pemakalah dalam pertemuan ilmiah 2) } & Lokal & Tidak ada \\
\hline & & Nasional & Tidak ada \\
\hline & & Internasional & Tidak ada \\
\hline 3 & \multicolumn{2}{|l|}{ Buku Ajar (ISBN)/ Bahan Ajar 3) } & Tidak ada \\
\hline 4 & \multicolumn{2}{|c|}{ Model/ Purwarupa/ Desain/Karya Seni/ Rekayasa Sosial 4) } & Tidak ada \\
\hline
\end{tabular}


Jurnal ABDINUS : Jurnal Pengabdian Nusantara, 2 (2), 2019, 108-114

Nur Amaliah, Ria Setyawati, Farida, Ida Suriana, Abdul Gafur

\begin{tabular}{llll}
\hline 5 & Teknologi Tepat Guna 5) & & Produk \\
6 & Tingkat Kesiapan Teknologi (TKT)6) & & 1 \\
7 & Hak Atas Kekayaan Intelektual (HKI) 7) & Paten & Tidak ada \\
& & Paten sederhana & Tidak ada \\
& & Hak Cipta & Tidak ada \\
& & Merek dagang & Tidak ada \\
\hline
\end{tabular}

\section{PELAKSANAAN}

Pelaksanaan dari kegiatan pengabdian kepada masyarakat tentang “Diversifikasi Produk Pangan Olahan Berbasis Buah Pepaya Dalam Meningkatkan Kesejahteraan Petani Karang Joang Balikpapan" dengan beberapa tahapan sebagai berikut:

1. Procurement (pengadaan alat dan barang)

Pada tahap ini melakukan pengadaan barang yang tepat dan sesuai dengan kebutuhan. Mencari harga yang tepat dan sesuai serta transparant dalam mendukung kegiatan pengabdian masyarakat ini.

2. Pelaksanaan Pelatihan

Pada tahap ini merupakan kegiatan dari program pelatihan yang terdiri kegiatan teori dan praktik. Kegiatan ini dilakukan selama 2 hari, pada hari pertama kegiatan yang dilakukan dengan memberikan teori dengan fokus pada materi pelatihan pengolahan produk pangan berbasis buah pepaya, pelatihan pembuatan P.IRT dan DEPKES, serta manajemen terkait organisasi kelompok tani. Pada hari kedua melakukan praktek pengolahan buah pepaya mini menjadi semprong pepaya (egg roll) pepaya dan abon pepaya.

Pelatihan secara teoritis dilaksanakan di kampus Politeknik Negeri Balikpapan diruang Restoran Tata Boga. Kegiatan praktik di laksanakan di ruang praktik (kitchen) Prodi Tata Boga Politeknik Negeri Balikpapan.

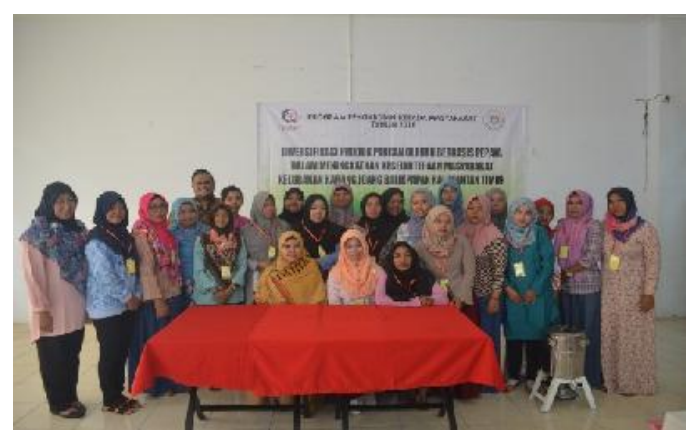

Gambar 1. Kegiatan Sosialisasi

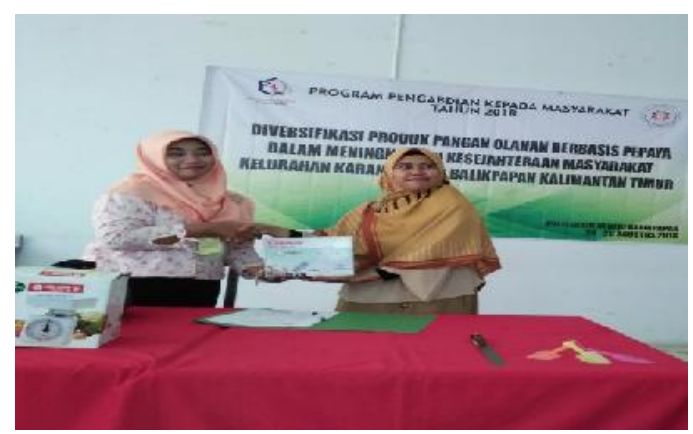

Gambar 2. Serah Terima Alat 


\section{Jurnal ABDINUS : Jurnal Pengabdian Nusantara, 2 (2), 2019, 108-114}

Nur Amaliah, Ria Setyawati, Farida, Ida Suriana, Abdul Gafur

3. Pendampingan

Pada tahap ini diberikan pendampingan secara berkelanjutan dan sistematis untuk memastikan kualitas produk yang dihasilkan layak untuk dipasarkan.

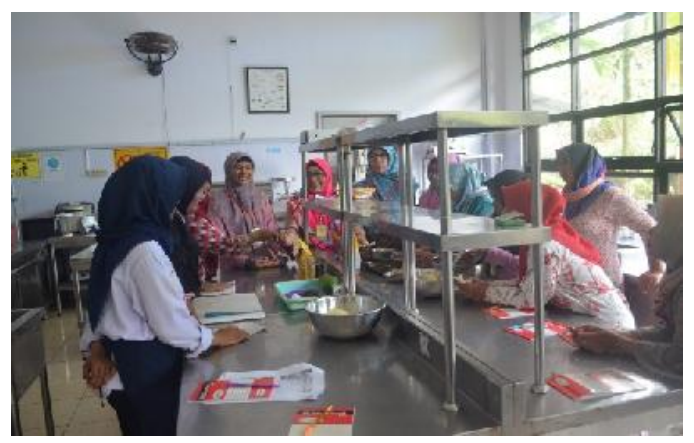

Gambar 3. Pelatihan Pembuatan Abon Pepaya

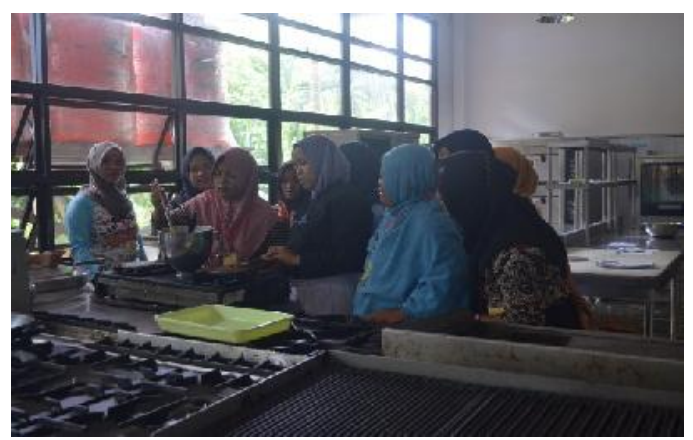

Gambar 4. Pelatihan Pembuatan Semprong Pepaya

\section{HASIL DAN LUARAN}

Hasil kegiatan sosialisasi pengabdian kepada masyarakat pada tanggal 25 - 26 Agustus 2018 dihadiri oleh Kelompok Wanita Tani Cempaka 19 yang berjumlah 20 orang. Kegiatan diawali dengan sosialisasi yang dilaksanakan pada tanggal 25 Agustus 2018 bertempat di Restoran Tata Boga Politeknik Negeri Balikpapan. Kegiatan berlangsung dengan lancar dan Kelompok Wanita Tani Cempaka 19 sangat antusias dengan materi yang diberikan berupa "Deversifikasi Produk Pangan Berbasis Buah Pepaya". Dengan menganekaragamkan produkproduk kuliner berbasis buah pepaya, Kelompok Wanita Tani Cempaka 19 dapat melakukan modivikasi produk antara lain membuat semprong pepaya dan abon pepaya. Selain pemberian materi terkait olahan pepaya, diberikan pula resep acuan pembuatan semprong dan abon pepaya serta teknik pembuatan agar pada saat produksi hasil yang diperoleh sesuai dengan standar produk.

Pengadaan alat berlangsung pada tanggal 25 Agustus 2018 di Restoran Tata Boga Politeknik Negeri Balikpapan. pengadaan alat diberikan untuk memenuhi kebutuhan produksi Kelompok Tani Cempaka 19 berupa alat spinner digunakan untuk meniris minyak pada produk abon papaya. Sedangkan cetakan semprong, mixer, spatula, sumpit, timbangan, dan pallet digunakan untuk produksi semprong papaya. Pengadaan alat ini bertujuan untuk memaksimalkan produksi olahan papaya agar mendapatkan produk yang sesuai dengan standar pemasaran. 


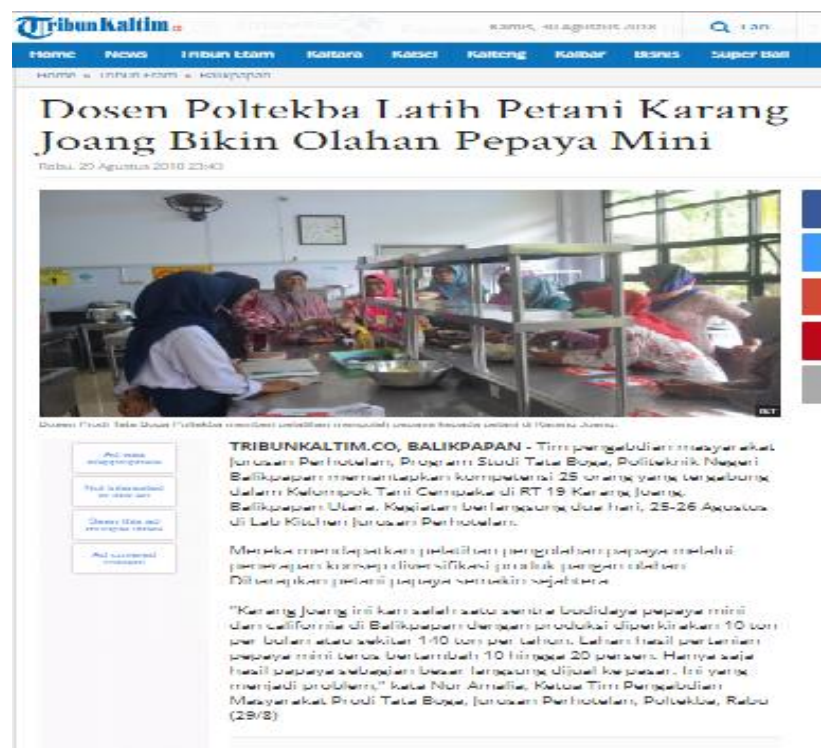

Gambar 5. Publikasi Koran

Pelatihan pengolahan berbasis papaya dilaksanakan pada tanggal 26 Agustus 2018 di Kitchen Tata Boga Politeknik Negeri Balikpapan. Pelatihan dilakukan dengan membagi 2 kelompok dari Kelompok Wanita Tani Cempaka 19 dan dilakukan rolling agar semua kelompok dapat membuat semua produk olahan dari papaya. Demonstrasi pelatihan pengolahan semprong papaya dan abon papaya dibimbing oleh tim pengabdian masyarakat sehingga hasil yang diperoleh lebih bagus dan layak untuk dipasarkan.

\section{SIMPULAN}

Simpulan yang diperoleh saat melakukan survey hingga pelaksanaan yaitu kurangnya pemahaman masyarakan akan pengembangan produk berbasis pepaya sehingga dalam pengabdian kepada masyarakat memberikan bantuan berupa sosialisasi berupa pemberian materi mengenai Diversifikasi Produk Pangan Olahan Berbasis Buah Pepaya serta pelatihan pembuatan produk papaya berupa abon pepaya dan semprong pepaya serta memberikan peralatan untuk menunjang pelaksanaan produksi ibu-ibu kelompok tani Cempaka 19 di Karang Joang.

\section{DAFTAR RUJUKAN}

Desrosier, N.W., 1988. Teknologi Pengawetan Pangan . Terj. Muchji Muljoharjo. Jakarta: UI Press 
Jurnal ABDINUS : Jurnal Pengabdian Nusantara, 2 (2), 2019, 108-114

Nur Amaliah, Ria Setyawati, Farida, Ida Suriana, Abdul Gafur

Syaefullah, Enrico., Purwadaria, Hadi K., Sutrisno., Suroso. 2007. Identifikasi Tingkat Kematangan Pepaya (Carica pepaya L) IPB 1 Dengan Pengolahan Citra Digital Dan Jaringan Syaraf Tiruan. Agritech, Vol. 27

Laporan Produktivitas Hasil Pertanian di Balikpapan (2015), Dinas Pertanian Kelautan dan Perikanan Kota Balikpapan, Kalimantan Timur

Suprana, Yayang Ade., 2012. Pembuatan Keripik Pepaya Mengguanakan Metode Penggorengan Vacuum Dengan Variabel Suhu dan Waktu. Laporan Tugas Akhir Diploma III Fakultas Teknik Univ. Diponegoro. Semarang. 